\title{
Addressing Facilitator-Related Issues as a Key Factor in Achieving SDG 4.6 in Ghana: The Case of the Ghana National Functional Literacy Programme
}

\author{
Dr. Susan D. D. Berdie \\ Faculty of Education and Entrepreneurship, Department of Educational Studies, Methodist University College \\ Ghana, PO Box DC940, Dansoman, Accra, Ghana
}

\begin{abstract}
The achievement of the Sustainable Development Goals globally is linked to its successful implementation in Ghana also. Ghana's Ministry of Education is working towards achieving Goal 4; "ensure inclusive and equitable quality education and promote lifelong learning opportunities for all" and its Indicator 6 which states, "by 2030 ensure that all youth and a substantial proportion of adults, both men and women, achieve literacy and numeracy". Ghana's Education Sector Strategic Plan (ESP) 2018-2030 enlisted 5 Key Performance Indicators to be led by the Complementary Education Agency for achieving SDG4.6 in Ghana. The Plan also identifies a number of challenges facing the Agency and planned a ministry of education-led institutional reform. This paper adopting a qualitative documentary analysis examines these 5 Key Performance Indicators against the recent past achievements of the Agency and how it prepares its critical functionaries; the facilitators to effectively deliver. The paper argues that a key input into quality non-formal education, especially adult literacy delivery, is the quality of facilitators and how effectively they perform amidst many challenges. The paper recommends among others that the reform by the MOE should focus on facilitation-related issues.
\end{abstract}

Keywords: Sustainable Development Goals, education, non-formal education, adult literacy, facilitation

DOI: $10.7176 / \mathrm{JEP} / 12-36-05$

Publication date: December $31^{\text {st }} 2021$

\section{Introduction}

The Education 2030 Framework for Action and the Incheon Declaration mandates countries to ensure the achievement of SDG 4; inclusive and equitable quality education and lifelong learning by all by 2030 (UNESCO, 2016). Indicator 6 of SDG Target 4 stipulates that "by 2030 ensure that all youth and a substantial proportion of adults, both men and women, achieve literacy and numeracy". Subsequent to this, the Ministry of Education in Ghana has also reviewed its strategic plan to align closely with the SDG Goal 4, the African Union Agenda 2063 and the overall National Development Plan (MOE, 2018a). The Education Strategic Plan (ESP) 2018-2030 is also based on a Sector Analysis Report (MOE, 2018b).

The MOE states in the ESP that 'The main intervention the Ministry of Education employs to improve literacy rates for those working in the informal economy is the National Functional Literacy Programme (NFLP)" (MOE, 2018b: 9). The ESP further justifies the need for functional literacy for youth and adults by stating that "Of those who complete nine years of basic education, only $54 \%$ of males and $43 \%$ of females acquire literacy skills that are likely to persist through adulthood. There is hence a strong need for adult literacy programmes, even for those who have attended formal schooling" (MOE, 2018b: 9). The new ESP 2018-2030 therefore has a strategic goal for non-formal education (NFE) under which target 4.6 falls; improved opportunities for non-literate youth and adults to have free access to meaningful quality education and training.

The MOE thus, considers non-formal education as a necessary complement to formal education, all in a lifelong learning framework in achieving the SDG4. The MOE has thus, outlined indicators for measuring the contribution of the non-formal education sector. The Monitoring and Evaluation (M\&E) Framework of the ESP provides guidance on how the Complementary Education Agency (CEA) formerly the Non-formal Education Division (NFED), the lead agency for NFE and the Ghana National Functional Literacy Programme (GNFLP) can plan and track its progress to ensure effective reporting to the MOE. This increases transparency and accountability. The CEA is expected to keep 5 Key Performance Indicators under close observation.

This paper is aimed as a response to the call at Incheon in 2015 for researchers to make contributions: to education development in general and policy dialogue in particular; to achieving the targets; to help chart progress, propose options or solutions and identify best practices that are innovative, scalable and transferable, to closing the funding gap ... (UNESCO, 2015: 59). The other justification from the same source requires that teachers and educators are empowered, adequately recruited, well trained professionals, qualified, motivated and supported within well-resourced efficient and effectively governed systems (UNESCO, 2015). Furthermore, the role played by an educational agent who ensures quality and equitable learning for all participants is acknowledged (ICDE, 2012; Bhola, 2000).

This paper now discusses Non-Formal Education (NFE) programmes, facilitation of adult literacy and non- 
formal education programmes, as against the indicators set out in the ESP 2018-2030 and argues that some facilitation-related issues found in a study earlier conducted on the GNFLP if not addressed could hinder the achievement of the goals set in the ESP and ultimately the SDG4.6.

\section{Facilitation}

NFE is education that is institutionalized, purposeful and scheduled by an educator or a facilitator. It is an addition, alternative and/or complement to formal education within the process of the lifelong learning of individuals (UNESCO, 2006). NFE is often a means of providing access to education for all and a rights issue. NFE includes programmes such as adult and youth literacy and education for out-of school children. It is targeted at participants acquiring or improving their life skills, work skills, and social or cultural development (UIS, 2012). This paper draws on the Facilitation Theory because of its focus on how adults are helped to learn and the implications for facilitation of English literacy in the GNFLP particularly and the local languages. I found it particularly useful to make sense of my data.

Just like any concept, facilitation has also attracted varied meanings. The Oxford Advanced Dictionary defines 'facilitate' as to make an action or a process possible or easier. Kato (2010:694) formulates it as 'seeking a set of useful tools' with which to administer organizational activities such as meetings that engender group collaborative projects. It is quite different from formal learning methods in school. Facilitation in the case of the GNFLP is how educators of adult non-literates organize and lead them with activities in a class situation to discuss issues that challenge their development and also enable them to acquire functional reading, writing and numeracy skills.

Facilitation as a concept was introduced into educational writings over a decade earlier by Carl Rogers, the American psychologist and adult educator (Brookfield, 1986). The facilitator is regarded as a change agent who provides practical advice and support to learners (Burrows, 1997). Facilitation is expected to create a supportive environment for knowledge construction by facilitators and learners (Burrows, 1997). According to Kato (2010), facilitation should be examined in two ways; 1) facilitation as utilization of a set of tools and techniques and 2) the process by which it is done. The paper now examines facilitation in these two ways.

\subsection{Facilitation as Use of Tools and Techniques}

Facilitation viewed as the use of a set of tools and techniques is the function of carefully selecting and combining a set of aids such as icebreakers, jokes, brainstorming, buzz groups and small groups, case studies, panel discussions, lectures, debates etc. to aid learning (Kato, 2010). Apart from the personal qualities required of facilitators, they are expected to use these various tools and techniques to make learning easy for their group members. Facilitators' effective use of these tools, however, depends largely on how much training they receive, how they think through the facilitation process, the leadership roles played and the learning they undertake (Kato, 2010). Facilitation in the GNFL depends on how managers and facilitators conceptualize facilitation, build capacity for their use as well as make provision for their use for effective adult learning.

\subsection{Facilitation as a Process}

Facilitation is a process of assuming leadership in overseeing and controlling the group's process through guiding participants to 'reflect on, intensify, and generalize their own and other group members' experiences' towards learning (Kato, 2010: 695; Brookfield, 1986). It also includes other leadership skills such as critical thinking, analytical, problem solving /conflict resolution, management, administrative and organizing skills, coaching, motivation, communication, collaboration, evaluation, interpersonal, mentorship, technical, and has emotional intelligence and passion for lifelong learning.

To be a facilitator is to act as a human catalyst, working the chemistry which turns a group of individuals into an operational team (Tagoe, 2013). The facilitator is central in creating the initial mood or climate for what happens in the learning context (McCaffery, Merrifield, \& Millican; 2007; Oxenham, 2003). Facilitators should, therefore, be trained in all these as well as content of instruction and methodology (Nicholas, Fletcher, \& Davis, 2012). In this way, facilitation will help draw out ideas and enhance understanding both by the facilitator and the learners who are engaged in a joint process of mutual learning (Kato, 2010).

Facilitation is also a collaborative and dialogical act through which the leader learns from the participants in the learning process in much the same way that the participants also learn from the leader (Brookfield, 1986; Freire, 1970). It is thus an influencing act. Praxis or action taking is placed at the heart of effective facilitation (Freire, 1970). A facilitative learning environment should be a place of shared love. However, that initial love to help may not be sustainable because the job involves too much giving of oneself (Berdie, 2013). The study underpinning this paper revealed that facilitators think they give too much of themselves. Has GNFLP staff been exposed to the related SDG4 goals they should be helping achieve as captured in the ESP 2018-2030?

The paper adopts a qualitative paradigm using documentary study to discuss facilitation using the case of the GNFLP. Among the documents examined is the report of a study conducted by the author of this paper on 
facilitation of English literacy classes in the GNFLP submitted for a doctoral qualification in 2017. The paper argues that facilitation is central to NFE programmes and thus neglecting facilitator-related issues will result into missing key indicators of success; in this case those in the ESP for NFE and the SDG4.6. The discussion now continues with a critical look at issues to address in the implementation of the strategies outlined in the ESP three years on.

\section{Issues to Address in the NFE Sector to Achieve the Targets of the ESP 2018-2030 and SDG 4.6 in GHANA}

3.1 Insufficient Resource Allocation to the Complementary Education Agency for Operations

A study undertaken by the author in 2017 revealed that inadequate, irregular and sometimes, non-release of funds had affected all sectors of the GNFLP including coordination of NFE in the country. This is despite the attempts made by the CEA even with the meager resources.

The programme was initially largely funded by the World Bank, DFID and others with some government input in its two phases which ended in 2006. Since then the government has sustained the programme but on very limited funding which affected all programme components requesting management undertaking some policy changes to sustain the running of the adult literacy classes. However, the achievement and plans overlook facilitation and capacity building of facilitators; pointing to facilitation not being considered critical to the success of the programme.

Thus, the perpetual stagnation of GOG funding below 1 per cent of the education budget has affected the delivery of NFE in the country. There is little left for financing the business of non-formal education in Ghana. In 2015 , government of Ghana budgetary allocation to the CEA was 0.2 percentage share of the 2015 total expenditure by level of education spending and type as Table 1A indicates. This fell to 0.0 per cent for 2 continuous years ( 2016 and 2017) and rose to 0.3 per cent in 2018. The GOG allocation has consistently never reached 1 per cent. The Agency has no other funding source. The tables below illustrate the situation clearly from 2015 and 2018 :

\begin{tabular}{|l|r|rr|r|r|r|}
\hline \multicolumn{2}{|c|}{ TABLE 1A: 2015 TOTAL EXPENDITURE BY LEVEL OF EDUCATION AND TYPE OF EXPENDITURE } & \multicolumn{1}{c|}{ \% } \\
\hline LEVEL & COMPENSATION (GHS) & $\begin{array}{l}\text { GOODS \& } \\
\text { (GHS) }\end{array}$ & SERVICES & ASSETS (GHS) & \multicolumn{1}{c|}{ TOTAL (GHS) } & $\begin{array}{l}\text { \% } \\
\text { Share }\end{array}$ \\
\hline PRE-SCHOOL & $400,098,152.0$ & $33,264,537.0$ & $25,771,062.0$ & $459,133,751.0$ & $5.3 \%$ \\
\hline PRIMARY & $1,186,928,317.0$ & $79,572,726.0$ & $52,020,295.0$ & $1,318,521,338.0$ & $15.2 \%$ \\
\hline JHS & $1,615,307,342.0$ & $69,178,986.0$ & $24,889,360.0$ & $1,709,375,688.0$ & $19.7 \%$ \\
\hline SHS & $783,938,235.0$ & $782,993,373.0$ & $523,974,267.0$ & $2,090,905,875.0$ & $24.0 \%$ \\
\hline NFED & $14,109,945.0$ & $407,777.0$ & 0.0 & $14,517,722.0$ & $0.2 \%$ \\
\hline SPED & $20,218,596.0$ & $9,219,039.0$ & $1,722,251.0$ & $31,159,886.0$ & $0.4 \%$ \\
\hline TVET & $60,440,013.0$ & $120,357,757.0$ & $31,556,677.0$ & $212,354,447.0$ & $2.4 \%$ \\
\hline TERTIARY & $1,120,929,408.0$ & $681,146,630.0$ & $286,053,478.0$ & $2,088,129,516.0$ & $24.0 \%$ \\
\hline $\begin{array}{l}\text { MGMT } \\
\text { AGENCIES }\end{array}$ & $\mathbf{7 1 4 , 1 1 8 , 6 6 4 . 0}$ & $35,387,213.0$ & $23,011,963.0$ & $772,517,840.0$ & $8.9 \%$ \\
\hline TOTAL & $\mathbf{5 , 9 1 6 , 0 8 8 , 6 7 2 . 0}$ & $\mathbf{1 , 8 1 1 , 5 2 8 , 0 3 8 . 0}$ & $\mathbf{9 6 8 , 9 9 9 , 3 5 3 . 0}$ & $\mathbf{8 , 6 9 6 , 6 1 6 , 0 6 3 . 0}$ & $\mathbf{1 0 0 . 0 \%}$ \\
\hline
\end{tabular}

Source: Ghana Ministry of Education, Planning, Budgeting, Monitoring and Evaluation (PBME) Division, 2020.

\begin{tabular}{|c|c|c|c|c|c|}
\hline \multicolumn{7}{|c|}{ TABLE 1D: 2018 TOTAL EXPENDITURE BY LEVEL OF EDUCATION AND TYPE OF } \\
EXPENDITURE \\
\hline \hline Level & Compensation & Goods \& Services & Capex & Total & $\%$ share \\
\hline \hline Pre-school & $1,263,425,553$ & $14,582,189$ & $37,023,955$ & $1,315,031,697$ & $10.3 \%$ \\
\hline Primary & $1,985,383,012$ & $33,862,468$ & $99,104,807$ & $2,118,350,287$ & $16.6 \%$ \\
\hline JHS & $1,839,603,141$ & $15,653,159$ & $35,822,091$ & $1,891,078,391$ & $14.8 \%$ \\
\hline SHS & $1,195,040,921$ & $722,559,696$ & $333,680,919$ & $2,251,28,535$ & $17.6 \%$ \\
\hline TVET & $90,322,537$ & $55,005,236$ & $20,915,589$ & $166,243,362$ & $1.3 \%$ \\
\hline SPED & $13,883,797$ & 39,811 & - & $13,923,608$ & $0.1 \%$ \\
\hline NFED & $41,834,741$ & 450,000 & - & $42,284,741$ & $0.3 \%$ \\
\hline Tertiary & $1,343,041,030$ & $944,853,071$ & $1,456,430,663$ & $3,744,324,765$ & $29.3 \%$ \\
\hline Management \& & & & & & \\
Subverted & $1,069,280,064$ & $118,346,041$ & $44,581,926$ & $1,232,208,030$ & $9.6 \%$ \\
\hline Total & $\mathbf{8 , 8 4 1 , 8 1 4 , 7 9 6}$ & $\mathbf{1 , 9 0 5 , 3 5 1 , 6 7 0}$ & $\mathbf{2 , 0 2 7 , 5 5 9 , 9 5 0}$ & $\mathbf{1 2 , 7 7 4 , 7 2 6 , 4 1 7}$ & $\mathbf{1 0 0 \%}$ \\
\hline Share & $\mathbf{6 9 . 2 \%}$ & $\mathbf{1 4 . 9 \%}$ & $\mathbf{1 5 . 9 \%}$ & & \\
\hline
\end{tabular}

Source: Ghana Ministry of Education, Planning, Budgeting, Monitoring and Evaluation (PBME) Division, 2020. 
TABLE 1B: SUMMARY OF TOTAL EXPENDITURE BY CEA BY TYPE OF EXPENDITURE FROM 2015-2018

\begin{tabular}{|l|l|l|l|l|l|}
\hline Year & $\begin{array}{l}\text { Compensation } \\
\text { GHC }\end{array}$ & $\begin{array}{l}\text { Goods \& Services } \\
\text { GHC }\end{array}$ & Capex & $\begin{array}{l}\text { Total } \\
\text { GHC }\end{array}$ & $\begin{array}{l}\text { Percentage of MOE } \\
\text { Expenditure }\end{array}$ \\
\hline 2018 & $41,834,741.0$ & 450.000 & - & $42,284,741$ & $0.3 \%$ \\
\hline 2017 & 614,240 & 575,996 & - & $1,190,236.0$ & $0.0 \%$ \\
\hline 2016 & 32,911 & 78,720 & - & $11,631.0$ & $0.0 \%$ \\
\hline 2015 & $14,109,945$ & $407,777.0$ & - & $14,517,722$ & $0.2 \%$ \\
\hline
\end{tabular}

Source: Ghana Ministry of Education, Planning, Budgeting, Monitoring and Evaluation Division (PBME), 2020.

Table IB above has illustrated clearly the situation of resource allocation to the Agency over the four years. Compared to the other agencies, this shows the level of neglect. For example, in $2015,15.2 \%$ of the education budget was allocated to the primary sector compared to the $0.2 \%$ of the NFED; two sectors handling basic education. The only education sector that also gets less than $1 \%$ is the Special Education Division of the GES. However, if the allocations to all the institutions under the formal pre-tertiary education sector are put together, it means a whopping $67.0 \%$ of the GOG budget went to the Formal sector compared to the $0.2 \%$ of the NFED. In 2016, and 2017, the NFED got $0.0 \%$ each respective year. The NFED only got a 0.1 increase from the $0.2 \%$ regular allocation to 0.3 in 2018. Although the GES allocation was reduced to 60.7 in 2018, the gap is still wide.

The ESP and the Sector Analysis Report captured the resource constraint of the GNFLP aptly below:

"NFE received the lowest amount of government education expenditure in 2015. Such expenditure are

almost entirely recurrent and demonstrate a low commitment to NFE programmes" (MOE, 2018a: 9).

Given that the CEA has been in a situation of using its allocation mostly for recurrent expenditure means there will be little left for goods and services. Of course paying salary with no allocation for people to do the work they are employed for is a recipe for no results or under performance. The current allocation should be increased as well as the management of the CEA and the Ministry exploring other funding opportunities such as internally generated funds and external funding. Without this intervention, it can be concluded that the NFE sector will continue to under-perform.

\subsection{Inadequate Capacity for Facilitating English Literacy}

The facilitator's role as an effective English language and Ghanaian language teacher demands expertise and team work. Freeman (1989) stresses that language teachers need to deal with applied linguistics methodology or language acquisition teaching in the English language as well as the facilitation role itself. In instances like this, the facilitator's competence at facilitating learning and also teaching the English language as a subject are of much benefit to the learners. Same argument applies to the facilitation of literacy in the local languages too. Learners with limited or no literacy in the language of literacy will perceive the facilitator as all knowledgeable, as the facilitator position also bestows leadership in knowledge. Thus, facilitators with weak English language and local language literacy competency will transfer such weakness to the learners thus affecting their ability to learn and use the language competently.

Asked whether or not he thought the staff facilitators were competent at facilitating English literacy for adult learners, a Municipal Coordinator affirmed their incompetence in view of poor training; no refresher training; inadequate primers, chalk and other class inputs.

When a facilitator was asked what the training content was, the following response was given:

The training covered how learners behave, the way they have to sit in the class, report writing as I have stated;

from the zonal report writing to limiting you to ... (Wilhelm Kuka, 2015).

From the response the training content did not cover English as a subject much more its teaching or facilitation. No wonder the facilitators also used a lot of translation into Ewe, the local language, as demanded by the learners, due to incomprehension when only the target language (English) was used probably due to the facilitators' inability to deliver effectively using only the English Language. This was so even for a local language neo-literate group now learning English irrespective of the learners' greatest expectation of communicating fluently in the English language in the shortest possible time. The assumption is based on their having been exposed already to local language literacy and adult learning. Justification for using translation method in the facilitation is given as follows:

Yes. When you go straight... when you start straight with the English without mixing it up, they won't talk, they won't talk. "Do you understand?", "Yes". Do this, they won't do. Because, it looks as if... and sometimes they will call you. When they close like this, three or four will call you "Facilitator, we can't understand it". "Facilitator, I don't attended school before, I don't go to school at all before, so Facilitator, please can you speak the Ewe small, so that we can also hear something?". That is why we are mixing the local and the English (Frank Sabah, 2015).

Despite this situation and opinions of the supervisors and facilitators of the programme, the planned activities to be undertaken by the CEA discussed earlier in this paper overlooked the central role facilitation plays in the successful delivery of literacy programmes (UNESCO, 2015; ICDE, 2012; Bhola, 2000). 
Will letting the facilitators lead English learning this way promote the quick competence that the learners seek to be functional in a country that has English as its official language? Doing that means the key position of facilitation and related issues has been lost on the management of the Agency in the preparatory activities for ESP achievement. Without the adequate preparation and deployment for facilitation of NFE activities, ESP goals and SDG Goal 4 will suffer in Ghana.

\subsection{Poor Training for Facilitation}

The study revealed that training and re-training of facilitators among others has also suffered. Furthermore, the effective participation of facilitators is critical to the achievement of all the 5 Key Performance Indicators (KPIs) listed in the new ESP; enrolment of face-to-face adult literacy programme; enrolment in newly created NFE programmes; number of new NFE programmes developed with textbook/content material (aggregate from baseline); number of new learning centres built; and proportion of non-formal graduates who access skills development opportunities (MOE, 2018a: 44). Weak facilitator capacity prevails in sub-Saharan Africa and in the GNFLP (Berdie, 2017; Dunne, Akyeampong, and Humphreys, 2007; UNESCO 2006; Bhola; 2000).

For the GNFLP, areas that have been greatly affected as revealed are the absence of training programmes, the short number of training days, and the non-provision of refresher training. Three days' training for leading English language adult learning without refresher training for the facilitator tasks them so much and ends up exposing the learners to doubtful learning outcomes. The need for refresher training was demanded in an expression as follows:

... Another one is about the refresher training. Yeah. Because, since 2009 or so, we have never had any refresher training. So, some of us are just building on the old things that we have learnt and the one that we were trained about the English class too for about only three days. So, it was not enough. So, I think a refresher course should be organized because things are changing. Things are changing, so we have to be... we have also got to be what... errr, we have to be abreast with time and something like that (Johnson Apreh, 2015).

Wilhelm, one of the respondents in the study thought NFED's inability to provide training on new ways of facilitating learning was de-motivating. In GNFLP, the Cascade Approach to Training model using the 'Trainer of Trainers' approach is adopted (Bhola, 2000). With this 'Cascade', content of the training is translated and implemented as understood by each level of trainers and is likely to be diluted as it reaches the classroom. The teaching of English language requires specialisation if learners are to graduate with English literacy competency. As seen above, most of the issues discussed above relate to training, re-training and the professionalization of the facilitators.

According to the performance indicators as captured in the NFE Indicators Framework in the ESP 2018-2030, 60 per cent of NFE facilitators should have been trained by 2021. Since 2017, no such training has been done by the CEA. It is also not covered in activities they plan to undertake soon. This is a clear sign of missing the achievement so desired by planners at the MOE. Should NFE be considered as really complementary to formal education, there is the need for adequate capacity for training adult educators as professionals with relevant qualifications. The Institute of Continuing and Distance Education (ICDE) of the University of Ghana, Legon used to offer certificate courses at Tsito. However, this has been discontinued. The Colleges of Education only focus on the training of formal school educators.

There is a need for policy on training and refreshing adult educators which will need to take into account the average base of competence required, the type and time of initial training and continuous professional development required to secure the adoption of appropriate instructional habits.

\subsection{Out-dated Curriculum and Inadequate Supply of Instructional Materials}

One of the greatest challenges facing facilitation of learning in the GNFLP is the inability of programme managers to regularly review and supply adequate and relevant instructional materials based on current and relevant curriculum to facilitators for use in the classes. GNFLP curriculum designers' expectations were that the Primer be used in all delivery; however the study revealed that it is only used as a guide to learners' social issues. Even though the GNFLP upheld Freirean principles of participatory learning and andragogic principles, there was much emphasis on drill, rote learning, memorization and the use of didactic methods during observation of facilitation of the English literacy classes. Secondly, it was observed that the capacity to lead a specialist subject such as English requires updated and requisite curriculum and sufficient primers to help these non-specialist English teachers and their learners.

In addition, the issue of ensuring connectedness of classroom activities to the world beyond the class and tapping experiences through a problem-based curriculum is also dependent on facilitator competence. This is based on the SDG emphasizing application of knowledge and skills to contribute to development. This assertion is supported by the findings in the study conducted for this paper as follows:

... English has become a second language for Ghanaians. So, helping somebody to know or read and write in English to improve his life is a great success or achievement because in the local languages something like the introduction of this mobile phone you cannot use the local languages alone...because most of the letters 
of the alphabet are not on the phone (Frank Sabah, 2015).

The facilitators focus more on grammar than on teaching reading, writing, numeracy and communication, through emphasis on identifying verbs, meanings of words, tenses, recall of words, spelling drills, correct pronunciation, among others. Yet, this situation presents the facilitators to the learners as the most knowledgeable persons. This situation, however, thus turns the facilitation into pedagogic and transmission mode.

The interview transcript from one of the facilitators also captures what ran through their responses when asked what difficulties they face in their facilitation work:

We have difficulties, we have difficulties, plenty difficulties. First mobility becomes a problem. Mobility is a problem because you may not be facilitating at where you are residing or you may have other classes, many classes under you.And secondly our primers are no more abundant, the Primer $1 \ldots$ We are even supposed to open other classes but there are no primers for learners so there is nothing you could do. So at times when you come to the office and there are no primers especially these English primers. We are short of this English primer. Very soon we will even complete the Primer one but the probability that they will even get the Primer two is a problem (Frank Sabah, 2015).

The success of the CEA will be measured also by the indicator on the number of new NFE programmes developed with textbook/content materials. So far, instead of the expected 3 required in the ESP Indicators, CEA achievements listed only one set of Basic English Primer 1, Basic Numeracy Primer 1 and their corresponding Facilitator's Manuscripts have been developed yet are awaiting procurement of printing services 3 years into the implementation of the ESP. These are even only for the face-to-face adult literacy programme. Certainly, at this rate the facilitators will not get the required numbers of updated and relevant curriculum and instructional materials to engage in their facilitation work. ESP NFE goals and SDG 4.6 goals will also be derailed.

The next section now discusses how the facilitators are supervised, monitored and evaluated to deliver effective service.

\subsection{Inadequate Supervision, Monitoring and Evaluation}

Supervision, Monitoring and Evaluation (SME) provide information for determining and improving time-on-task and facilitator regularity. These involve organizing and ensuring the availability of all needed resources for creating a favourable learning environment. The facilitators believe facilitation bestows leadership and power on the facilitator which could be individually misused if there were no supervisors to guide their facilitation frequently. It was reported that irregular monitoring and supervision visits by their superiors were some demotivating factors listed by these staff facilitators, although they would not consider leaving the job. The facilitators and their learners need programme implementers to support them on the field. This was captured by Davida when asked whether or not she gets supervised:

No, no. Only Auntie Cecie Wuyor. The rest don't... at least you know as human beings you have to encourage us; they have to come and encourage them. Even they can come and then sometimes facilitate, tell them something, something new. But always, you know, the same face every day (Davida Duah, 2015).

Asked whether or not she writes these in her report to the managers she answered in the affirmative and added that:

I will say ever since we started this class, this is the second time the Regional Director visited us. Yes. Every day he will promise, "Davida, I will come ooh, tell them I'm coming; tell them". So you know, so this time if you even tell them somebody will come and visit us, they don't take it ... (Davida Duah, 2015).

Although programme administrators at all levels will blame their inability to supervise and monitor due to financial and logistical challenges, it could also be blamed on the attitude of the administrators who may not attach importance to supervision and monitoring visits because they lack an understanding of the importance of such visits for creating the necessary environment for good facilitation. The facilitation itself and the administrative roles should be evaluated periodically to determine whether or not facilitation experiences in adult literacy classes are meeting the expectations of the participants and the planners. Tracking the performance of planned activities, in this case the ESP targets and indicators engender a spirit of continual learning, capacity development, risk monitoring as well as enhancing accountability and transparency (MOE, 2018a; World Bank, 2012).

The Education Strategic Plan has outlined a monitoring and evaluation framework for the whole NFE sector including the GNFLP. As at this year, 2021, four annual monitoring visits should have been undertaken by the CEA to the field, but this has not been possible by the agency and neither has the Planning Budgeting, Monitoring and Evaluation (PBME) unit of the MOE, responsible for monitoring the M\&E Framework of the EP 2018-2030 shown any interest. Reports from the CEA should be verified to ensure classes are really existing and doing what they are supposed to be doing; facilitating adult literacy and learning. Obviously, the targets set for the NFE sector are being missed.

Although this situation could be due to institutional leadership inaction, however, as this paper has been arguing, if the funding situation is not considered as necessary in ensuring that NFE is really complementary to formal education, and close attention paid to the CEA towards improvement, the failures of the agency will become 
clogs in the wheel of the success of the Ministry's SDG 4 implementation.

\subsection{De-Motivation and Poor Remuneration of Facilitators}

The issue of the motivation and remuneration of facilitators were revealed during the study as captured below:

I have never gone to leave since 2004.... And another one also is about the... about promotion. I may say some of us were employed in 2004 and some also came around 2009. But you'll see that their rank or their grade is higher than ours. Meanwhile, they've been employed under us, something like that so I think ... The same qualification. And you'll see that the salary too there is a difference. Theirs are higher than ours. ... So, but now that some of us have gone further, to further our education, we put in what... application for upgrading but as at now, we have not heard anything about that (Wilhelm, 2015).

Thus, unfair employment and promotion practices and no leave from work are management lapses that have challenged the workings and commitment of facilitators. CONFINTEA VI noted these issues because 'improving training, capacity-building, employment conditions and the professionalization of adult educators' is critical (UIL, 2009 , p. 41). This paper argues that fair employment and management of human resource underpins the successful achievement of ESP non-formal education targets as well as the SDG 4 in Ghana.

\section{Conclusion}

The Education 2030 Agenda and the Incheon Declaration have promoted the review of education systems in the world. Ghana also developed a new ESP which seeks to ensure holistic quality education for all in a lifelong learning framework through and thus included complementary non-formal education including adult literacy as one of its strategies.

It has been 3 years into the implementation of the Ghana ESP. However, it seems the CEA/ NFED is not keeping up with achieving the Key Performance Indicators outlined for the GNFLP and indeed the NFE sector. This paper has highlighted based on the findings of a study conducted by the author in 2015 , the chronic underfunding confronting the CEA which has resulted into the underestimation of the centrality of facilitation in the implementation of the GNFLP. It is critical to sustain the initial motivation of these facilitators who very often need to demonstrate lots of love and commitment as part of the facilitation role through addressing the funding gap and the several related issues the study unearthed if the GNFLP will achieve the KPIs. Doing so will also contribute to the MOE achieving quality holistic education for all and the global meeting of the SDG 4.

All these factors, programme-related and facilitator-related, need to be planned for urgently, administered and constantly monitored and evaluated by the CEA and the MOE to enhance facilitation and the achievement of the indicators for adult functional literacy and SDG 4:6.

Given that the CEA has been depending on government funding mostly for recurrent expenditure but also managed to do some foundational works, it can be firmly concluded that if no extra funding is sought, the indicators set for achievement by the SDG 2018-2030 will not be achieved.

\section{Recommendations}

As non-formal education has been fully recognised as complementary to formal education in the ESP, the MOE should strengthen its monitoring of the CEA to ensure that it is meeting its indicators on a timely basis. It is not an organisation that should be ignored if Ghana is to provide holistic education in a lifelong learning framework as sought by the SDGs.

Secondly, close monitoring will also ensure offering assistance to the Agency to identify critical priority activities and source for other sources of funding. Strong advocacy for increased funding from government and other sources should be pursued for the CEA in addition to aiding the CEA.

Furthermore, it may be relevant to run a lean organisation. As discussed earlier about staff being paid regularly with almost all the budgetary allocation leaving very little for services and capital expenditure to enable these staff perform, it seems appropriate to consider staff rationalisation. Thus, the institutional reform planned by the Ministry and the Agency should be prioritised in order to address the employment capacity issues. This will be in a situation in which it is highly impossible to greatly increase funding to the CEA. This will ensure the remaining staffs get the resources needed to do their work effectively and efficiently.

In addition, the professionalization of facilitators and implementers of adult literacy and NFE should be pursued as a matter of urgency. That will attract tertiary level educators and commensurate remuneration of these professional NFE facilitators and their sustained motivation and commitment. This can be done through ensuring that NFE courses are run in the existing Colleges of Education, thus, discontinuing the Trainer of Trainers method of equipping NFE facilitators. NFE facilitation certificate courses can also be offered by these institutions to ensure that lifelong learning is promoted for re-skilling by the current staff etc.

Lastly, the centrality of facilitation should be the focus of the reform where light is shed on facilitation as being critical to the continued existence of the organisation thus addressing management lapses such as nonplanning of leave for facilitators and promotion issues involving strong stakeholder consultation. For, no leave and 
non-promotion issues are against the Labour law of the country.

\section{References}

Berdie, S. D. D. (2013). An investigation into factors underlying volunteerism of adult literacy class facilitators in Ghana. Unpublished assignment for the Professional Doctorate of Education, Brighton: University of Sussex.

Berdie, S. D. D. (2017). Facilitation of Adult Literacy: A case within the Ghana National Functional Literacy Programme. Unpublished Dissertation for the Professional Doctorate of Education, Brighton: University of Sussex.

Bhola, H. S. (2000). A discourse on impact evaluation: A model and its application to a literacy intervention in Ghana, Evaluation, 6(2), 161-178.

Brookfield, S. D. (1986). Understanding and facilitating adult learning: A comprehensive analysis of principles and effective practices. Milton Keynes: Open University Press.

Burrows, D. (1997). Facilitation: A concept analysis. Journal of Advanced Nursing. 25(2), 396-404. http://onlinelibrary.wiley.com/doi/10.1046/j.1365-2648.1997.1997025396.x/abstract

Dunne, M., Akyeampong, K., \& Humphereys, S. (2007). School processes, local government and community participation: Understanding access. CREATE Pathway to Access-Research Monograph No. 6. Brighton, University of Sussex

Freire, P. (1970). Pedagogy of the Oppressed. New York: Herter \& Herter

Freeman, D. (1989). Teacher training, development and decision making: A model of teaching and related strategies for language teaching. TESOL QUARTERLY, 23(1), 27-45

ICDE. (2012). Adult Education: ADLT 101 Introductions to Adult Education. Accra: Institute of Continuing and Distance Education, University of Ghana.

Kato, F. (2010). How we think and talk about facilitation. Simulation and Gaming. 41(5), pp. 694-704.

McCaffery, J., Merrifield, J., \& Millican, J. (2007). Developing adult literacy: Approaches to planning, implementing and delivering literacy initiatives. Oxford: Oxfam GB

MOE. (2018a). Education Strategic Plan 2018-2030 (ESP), Accra: Ministry of Education. https://www.globalpartnership.org/content/education-strategic-plan-2018-2030-ghana

MOE. (2018b). Education Sector Analysis Report. Accra: Ministry of Education. https://www.globalpartnership.org/content/ghana-education-sector-analysis-2018

Nicholas, K., Fletcher, J., \& Davis, N. (2012). Raising numeracy and literacy to improve vocational opportunities, Journal of Vocational Education and Training, 64(4), 433-451 http://www.tandfonline.com.ezproxy.sussex.ac.uk/doi/pdf/10.1080/13636820.2012.727850

Oxenham, J. (2003). Review of World Bank operations in support of adult basic education with literacy in Indonesia, Ghana, Bangladesh, Senegal, and Côte d'Ivoire, 1977-2002. Human Development Education Network. Washington, DC: The World Bank,. First draft March.

Tagoe, M.A. (2013). Facilitation. Lesson notes prepared for Institute of Continuing and Distance Education programme, Accra: University of Ghana.

UIS. (2012). UNESCO/International Bureau of Education. http://www.ibe.unesco.org/en/glossary-curriculumterminology/n/non-formal- education

UNESCO. (2015). The Incheon Declaration, Education 2030: Toward inclusive and equitable quality education and lifelong learning for all. http://en.unesco.org/world-education-forum-2015/Incheon-declaration

UNESCO. (2006). Education for all Global Monitoring Report 2006: Literacy for life. Paris: UNESCO.

World Bank. (2012). Designing a results framework for achieving results: A how-to guide, Independent Evaluation Group, Washington DC: World Bank. http://siteresources.worldbank.org/EXTEVACAPDEV/Resources/designing_results_framework.pdf 